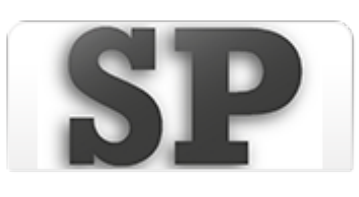

Sociedades precapitalistas ISSN: 2250-5121

publicaciones@fahce.unlp.edu.ar

Universidad Nacional de La Plata

Argentina

\title{
La construcción de la hegemonía pelaire en la protoindustria textil murciana
}

\author{
Fazzini*, Mauro \\ La construcción de la hegemonía pelaire en la protoindustria textil murciana \\ Sociedades precapitalistas, núm. 10, 2020 \\ Universidad Nacional de La Plata, Argentina \\ DOI: https://doi.org/10.24215/22505121e046
}

Atribución no comercial compartir igual (CC BY-NC-SA) 4.0 
Dossier: Formas de explotación del trabajo y relaciones laborales en sociedades preindustriales

\section{La construcción de la hegemonía pelaire en la protoindustria textil murciana}

The construction of the pelaire's hegemony at the murcian textile proto-industry

Mauro Fazzini**

DOI: https://doi.org/10.24215/22505121e046

Universidad Nacional de La Plata Consejo Nacional de

Investigaciones Cientificas y Tecnológicas, Argentina

maurofazzini89@gmail.com

Recepción: 11 Mayo 2019

Aprobación: 22 Julio 2019

Recepción: 11 Mayo 2019

Aprobación: 22 Julio 2019

\section{ReSUMEN:}

El presente artículo se propone indagar en los fundamentos de la construcción del poderío económico de la elite dirigente del gremio pelaire al interior de la protoindustria textil murciana, desde el último cuarto del siglo XIV hasta fines del siglo XV. Para ello daremos cuenta de los factores de carácter político-institucional que permiten que el sector dirigente de esta corporación subordine a buena parte del artesanado textil local y llegue a disputar el abastecimiento pañero de la ciudad con el sector del capital comercial representado por los traperos murcianos. Con este objeto analizaremos la incidencia de la regulación productiva impulsada por el sector dirigente de este gremio en la construcción de relaciones de explotación.

Palabras Clave: Pelaire, Protoindustria, Regulación productiva.

\section{Abstract:}

This article seeks to explain the construction of the economic power of the authorities of the fuller's guild, between the last quarter of the 14th century up to the final years of the 15th century. Whit that purpose, we will explain the political and institutional elements which allows the authorities of this guild to subordinate the local textile craftsmen and dispute whit the murcian merchants the textile supply in the city. For that, we will analyze the rol of the productive regulation proposed by the fuller's authorities in the exploitation of labour. Key Words: fuller- proto-industry-productive regulation 1. Introducción

KEYWORDs: Fuller, Proto-industry, Productive regulation.

\section{INTRODUCCIÓN}

En el presente trabajo buscaremos analizar el desarrollo de una elite empresarial al interior del gremio de los pelaires en el marco de la protoindustria textil murciana, desde el último cuarto del siglo XIV hasta fines del siglo XV. Para ello daremos cuenta de los factores de carácter político-institucional que permiten que el sector dirigente de esta corporación subordine a buena parte del artesanado textil local y llegue a disputar el abastecimiento pañero de la ciudad con el sector del capital comercial representado por los traperos murcianos. Con este objeto analizaremos la incidencia de la regulación productiva impulsada por este gremio en la construcción de relaciones de explotación.

Buscaremos demostrar que la elite pelaire posee cierta capacidad de presión sobre el concejo, lo que le permite extender la jurisdicción original de su corporación en pos de regular el trabajo del resto de los oficios textiles, subordinándolos de forma progresiva durante el transcurso del siglo XV. Ahora bien, proponemos a

\section{NoTAS DE AUTOR}

* El autor es Profesor de Enseñanza Media y Superior en Historia por la Facultad de Filosofía y Letras (UBA) y doctorando en Historia por la misma facultad. Su investigación doctoral versa sobre la historia económico-social del artesanado murciano durante la Baja Edad Media. Ha formado parte de la cátedra de Historia Medieval (Astarita) de la Facultad de Filosofía y Letra (UBA) en calidad de adscripto. A la vez, integra grupos de investigación sobre Historia Medieval. 
modo de hipótesis que la permeabilidad concejil al interés de la elite pelaire está en función al desempeño de esta corporación en la supervisión de la calidad de la producción textil importada. En un contexto en el cual la producción local no da abasto, el concejo debe permitir la entrada de productos foráneos, pero depende del oficio de la pelairía para corroborar que estos no presenten fallas en su elaboración.

Comenzaremos con una breve descripción del proceso productivo, que permite identificar a los actores sociales relevantes. Luego, pasaremos al análisis del proceso de construcción de la hegemonía de los pelaires sobre el resto de los productores textiles; proceso que, como veremos, atraviesa distintas etapas entre fines del siglo XIV y fines del XV.

\section{EL PROCESO PRODUCTIVO TEXTIL}

La elaboración de un paño resulta sumamente compleja en tanto requiere de múltiples operaciones con diversos grados de calificación. ${ }^{1}$ En primer lugar, existen una serie procedimientos preliminares destinados a preparar la lana para ser tejida. Tras el esquileo, la lana (lavada) en bruto se trasladaba a los centros urbanos donde se vendía al por mayor. Una vez adquirida por aquel que iba a emprender su manufactura (trapero, pelaire, etc.) se llevaban adelante una serie de operaciones que tenían por objeto preparar la lana para el hilado, a cargo de cardadores y peinadores. Estos artesanos eran asalariados que trabajaban en el domicilio del dueño de la lana, generalmente un mercader o un pelaire. ${ }^{2}$ Estos carecían de calificación y de capacidad de acción independiente. Debemos destacar que cardadores y peinadores estaban subordinados dentro del oficio de la pelairía, como oficios menores y carentes de derechos. ${ }^{3}$

Una vez concluidas estas operaciones se procedía a la hilatura, operación femenina por excelencia que servía como un complemento en los ingresos de la unidad doméstica (Martínez Martínez, 1988: 38; Iradiel, 1973: 192; Córdoba de la Llave, 2017: 72). ${ }^{4}$ La bibliografía especializada tiende a ubicar a esta actividad en el ámbito rural, aunque la documentación también admite la existencia de hilanderas urbanas (Martínez Martínez, 1988: 38; Iradiel, 1973: 192). ${ }^{5}$ Finalizado el hilado se procedía al urdido, que al igual que aquel era una actividad femenina y asalariada. Este consistía en colocar los hilos en la urdidera para luego pasarlos al telar y así formar la urdimbre o lizo del tejido. La urdimbre determinaba la cantidad de hilos que después tendría el paño, siendo las calidades superiores las que llevan mayor cantidad.

Tras el urdido se daba paso a la textura. Esta es la primera actividad compleja de la cadena productiva y, por ende, requería de una elevada calificación por parte de sus ejecutores. Esta consistía en entrelazar la trama con la urdimbre mediante la utilización del telar. La centralidad de la operación para establecer la calidad y el costo final del paño explica el especial interés por regularla. En contraposición a los artesanos anteriormente descriptos, los tejedores tenían capacidad para accionar independientemente y estaban organizados en un gremio autónomo. De ahí que pudieran ofrecer resistencia a la avanzada pelaire.

Una vez tejido el paño, se llevaban adelante una multiplicidad de operaciones destinadas a procurar un acabado más perfecto, limpiándolo de sus impurezas con el objeto de darle una apariencia uniforme y aumentar así su valor comercial. En este punto intervenía el oficio de la pelairía para llevar adelante una serie de operaciones que componían el adobado. Buena parte de las mismas se realizaban en molinos traperos. ${ }^{6}$

Los mejores paños, una vez batanados, eran tundidos. La tundidura consistía en igualar el pelo del paño mediante tijeras cortando el pelo a la misma altura. En un principio esta era una operación poco frecuente en Murcia. Dicha actividad fue adquiriendo cada vez más importancia en el transcurso del siglo XV, lo que redundó en un salto en calidad en la pañería murciana. Los artesanos que practicaban este oficio estaban incorporados al gremio de los pelaires, aunque sin derechos plenos, lo que facilitaba su subordinación económica. Esto será un foco de conflicto que analizaremos en el trabajo.

Por último, se procedía al tintado de los paños. Si bien podía realizarse en distintos momentos del ciclo textil, en la pañería murciana se realizaba usualmente al final. La operación estaba basada en la inmersión del 
paño en soluciones de materias colorantes y mordientes que actuaban como fijadores del color. Esta actividad resultaba fundamental para determinar la calidad del producto final. La tintura era sumamente costosa dado que dependía de materias primas importadas, controladas por el capital italiano. Esto generaba una barrera de entrada a la profesión, lo que convertía al gremio de los tintoreros en uno de los más exclusivos de la ciudad. Esta actividad mantendrá su independencia con respecto al empresariado pelaire durante el período estudiado, lo que aparece como un límite a la integración vertical de la protoindustria murciana. ${ }^{7}$

En síntesis, existe una gran diversidad al interior del artesanado textil murciano. Por un lado, se observan una serie de oficios de escasa calificación. Los artesanos que los ejercen carecen de capacidad de acción independiente. Cardadores y peinadores abocados a la preparación de la lana e hilanderas y urdidoras, insertas en las primeras etapas de la confección del paño, dependen por completo del dueño de la materia prima, generalmente mercader o pelaire, para quien trabajan a cambio de un salario.

Por el otro, se encuentran aquellos oficios con un elevado nivel de complejidad. En primer lugar, la textura, fundamental para determinar la calidad del paño y controlada por artesanos con capacidad de elaboración propia, agrupados en una corporación que vela por sus intereses. En segundo lugar, las operaciones de acabado, controladas por pelaires y tundidores. Estos comparten la corporación, aunque los últimos se encuentran subordinados y carecen de capacidad decisoria. Como veremos, es al interior del gremio de los pelaires que emergen acumuladores capitalistas. Por último, el tintado, operación costosa y de vital importancia, controlada por el gremio de los tintoreros. Estos artesanos mantendrán su independencia con respecto a los señores de paño.

\section{REgulación de LA PAÑERía MURCiANA Y CONSTRUCCión DE LA HEGEMONía PELAIRE}

Como hemos adelantado en la introducción, la corporación pelaire tiene la capacidad de presionar al concejo en pos de trascender los límites de su jurisdicción original y así avanzar por sobre las condiciones de trabajo del resto del artesanado textil. La fragmentación del proceso en múltiples unidades artesanales independientes, si bien favorece la emergencia de agentes que lo cohesionen, implica la ausencia de mecanismos de control intrínsecos al proceso de trabajo. ${ }^{8}$

Por ende, la regulación productiva será fundamental para que la elite dirigente del oficio de la pelairía construya su poder de mando en el marco de una industria descentralizada. Más allá de la independencia formal de los artesanos que participan en las distintas etapas del proceso productivo, pretendemos indagar en las formas de dirección de este por parte de un sector que tiende a dominar el conjunto de la producción. ${ }^{9}$

\section{A. Los primeros avances: fines del siglo XIV y comienzos del XV}

En esta primera etapa, la corporación pelaire busca avanzar por sobre las prerrogativas del oficio de los tejedores, sin registrarse conflicto alguno con otros colectivos textiles. Sin embargo, el concejo no se presentará permeable a los requerimientos pelaires.

La primera puja entre tejedores y pelaires que tenemos documentada data de 1374. En ese año, los veedores de ambos se disputan la jurisdicción sobre el caso de un paño defectuoso propiedad del trapero judío Haym Aventuriel. El paño en cuestión presenta problemas de tejido, pero el error fue hallado por un pelaire cuando se disponía a proceder con el adobo, de ahí que ambas corporaciones se disputen el derecho a juzgar los defectos de esta pieza. En una primera instancia, los jurados del concejo fallan a favor de los pelaires. Sin embargo, tras apelar a los jueces concejiles, los veedores de los tejedores logran que la sentencia sea revertida, obteniendo así la jurisdicción sobre el caso. ${ }^{10}$

Si bien no tenemos registros de casos similares durante las décadas siguientes, podemos inferir que se habrían reiterado pues en 1408 los gremios de tejedores y pelaires acuerdan acotarse a sus respectivas 
jurisdicciones para evitar una escalada en el conflicto entre ambos oficios. Estas corporaciones negocian el acuerdo sin injerencia de las autoridades municipales, para luego presentarlo ante estas para que sea aprobado. ${ }^{11}$

Sin embargo, la paz fue efímera. A pocos días de rubricado el acuerdo, los veedores de los tejedores denuncian intromisiones por parte de los pelaires en el momento en que sus paños son examinados por el almotacén ${ }^{12}$ en la calle de la trapería. ${ }^{13}$ Por esta razón piden que se les otorgue un nuevo lugar para que sea examinado su trabajo, ya que

sy en la dicha call ellos lo auian de judgar no se podrían escusar muertes de omes e otros males e daños; los quales sy acaesçiesen no seria seruiçio de Dios ni del rey nuestro señor ni onrra de la dicha çibdat ni pro e bien del dicho ofiçio, ca pues ellos no fablauan en el judgado de los dichos perayres ni del su ofiçio tanpoco, e menos era razon que los dichos perayres fablasen en el ofiçio de los dichos texedores (Martínez Martínez, 2000: 40).

Se observa la insistencia de los pelaires para inmiscuirse unilateralmente en la supervisión de la tejeduría. Ante la amenaza de los menestrales agraviados, el concejo otorga un nuevo lugar para la inspección de su trabajo. ${ }^{14}$

Estos primeros embates de la corporación pelaire no logran quebrar la resistencia de los tejedores, quienes se amparan en la protección concejil. Recién en 1416, aquella alcanza su primera victoria. En dicho año, representantes de este gremio, solicitan que los peines con los que se realiza el tejido sean ensanchados, en pos de obtener paños “mas paresçientes e vendables e prouechosos" (Martínez Martínez, 2000: 47). Esta es una intervención directa sobre los medios de producción de los tejedores con el objeto de adaptar a la producción textil murciana a los patrones de la nueva pañería. ${ }^{15}$ El concejo accede, estableciendo un plazo de 30 días para que los tejedores adapten sus telares. ${ }^{16}$

En este período, el registro documental sugiere cierto grado de desarrollo empresarial por parte de un sector pelaire, aunque este se encontraría en una etapa inicial. En este sentido, no encontramos evidencias sobre el control de materias primas por parte de estos artesanos enriquecidos. Sin embargo, existen referencias sobre pelaires que compran paños a tejedores, lo que podría interpretarse como un elemento propio del Kaufssystem, en tanto los productores trabajan con materia prima propia. ${ }^{17}$ Asimismo, ciertos pelaires también operan como gestores para otros mercaderes-fabricantes, que probablemente no provengan del ámbito artesanal. ${ }^{18}$ En este caso se sirven del conocimiento específico del pelaire sobre el proceso productivo así como de las condiciones locales.

En estos años, el oficio de la pelairía no desempeña un rol especial en el control de la calidad de la producción importada de las aldeas y villas menores murcianas, a diferencia de lo que sucederá más adelante. Es más, en este período el concejo se presenta inflexible con respecto a la entrada de paños e hilazas de áreas rurales para ser finalizados en la ciudad. Lejos de regular esta práctica, se instrumentan medidas represivas, aduciendo la baja calidad de estos paños. ${ }^{19}$

\section{B. La consolidación del poderío económico pelaire: de mediados a fines del siglo XV}

En este período la elite pelaire irrumpe como un actor económico de peso en la producción textil murciana. Resulta determinante el vuelco en el accionar del concejo, que comienza a interceder de forma favorable a los pelaires. Esto permite que la elite pelaire logre una regulación productiva acorde a sus necesidades de acumulación.

Luego de la imposición de paños más anchos a los tejedores en 1416, no tenemos información sobre otras solicitudes de la corporación pelaire que tengan el objeto de regular la producción de otros colectivos textiles por un lapso de treinta años. Habrá que esperar hasta 1446 para encontrar unas peticiones extensas por parte 
de los representantes de este gremio que abarcan distintos aspectos de la producción textil, apuntando a elevar su calidad. ${ }^{20}$ Estas se centran en los paños veintiunos. ${ }^{21}$

Por un lado, los pelaires solicitan que los tejedores aumenten la cantidad de lana dedicada a estos paños, a lo que el concejo accede. En un primer momento, los veedores de los tejedores son los encargados de supervisar la correcta elaboración de estos paños. Nueve años después, ante el incumplimiento de esta ordenanza, los veedores de los pelaires quedarán facultados para examinar este tipo de paños, extendiendo su jurisdicción original. ${ }^{22}$ A la par, en las peticiones de 1446 los representantes de la pelairía buscan regular por primera vez el trabajo de los tintoreros. En este caso, denuncian fallas en la tintura de brunetas y veintiunos por no ser teñidos en frío y no aplicarse el alumbre de forma correcta. ${ }^{23} \mathrm{El}$ concejo también hace lugar a este pedido.

El objetivo manifiesto es imitar a la pañería valenciana. Esto permitiría elevar la calidad de estos paños para que "sean mas loados e mas preçiados cada e quando de aqui ouiesen de salir a otras partes" (Martínez Martínez, 2000: 73). De esta manera, los representantes de la pelairía explicitan que la necesidad de obtener paños de mayor calidad apunta a lograr que se puedan vender fuera de la ciudad, probablemente en las villas menores de la región de Murcia.

En el mismo conjunto de peticiones, los representantes de la pelairía pretenden que el concejo vete la entrada de paños aragoneses en tanto en Murcia "ay e abra en ella tan buenos paños e mejores que en Aragon, e mas razon es que los vuestros menestrales ayan el prouecho con vosotros que no los estrangeros" (Martínez Martínez, 2000: 73). El concejo responde que prohibirá su entrada solo si primeramente se producen en la ciudad paños suficientes como para abastecer al mercado local. En este sentido, la prioridad concejil pasa por lograr que la ciudad no carezca de productos textiles. Volveremos sobre esta cuestión más adelante.

Resulta interesante poner en relación la normativa productiva impulsada por los representantes pelaires con el reclamo proteccionista. En este sentido, el intento de lograr el incremento de la calidad de la producción persigue obtener paños superiores que estén a la altura de los foráneos. ${ }^{24} \mathrm{~A}$ la par, se necesita de un mercado cerrado para apuntalar a la pañería murciana. Ambos reclamos dan la pauta de la existencia de una elite empresarial dentro de la corporación pelaire que comienza a estar en condiciones de organizar la producción local y de competir con la producción extranjera, pero que necesita de la intervención concejil para consolidar su posición.

En este punto se puede observar que es la propia corporación la que promueve un salto en calidad en la fabricación textil para lo cual impulsa la adopción de un nuevo marco regulatorio. ${ }^{25}$ Esto contradice las tesis del enfoque liberal tradicional, cuya versión actualizada encontramos en Ogilvie (2004: 30), según la cual la normativa gremial tiende a generar una osificación del aparato productivo, impidiendo el desarrollo de cambios cualitativos que solo serían posibles en el contexto del libre mercado.

Por último, en las peticiones presentadas en 1446, los representantes de la pelairía abren un foco de conflicto con los traperos de la ciudad que se extenderá durante toda la segunda mitad del siglo XV. Estos actúan como señores del paño elaborando textiles por encargo, actividad que combinan con la importación lisa y llana. Los veedores del gremio solicitan poder inspeccionar las tiendas de estos mercaderes y así corroborar que los paños hayan sido adobados de forma correcta, a lo que el concejo accede, participando del control también a los tejedores y a los ejecutores de la ciudad. Hasta ese momento, los veedores de la pelairía solo podían controlar que los menestrales pertenecientes a dicho gremio hubiesen realizado su labor con idoneidad solamente en el marco de los talleres. ${ }^{26}$

En este punto, la regulación actúa como un instrumento propio de la lucha de clases, en tanto la elite pelaire busca limitar la competencia de los mercaderes locales a partir de la inspección de sus tiendas. Más allá de que la ampliación de la jurisdicción gremial pueda evitar fraudes productivos, ${ }^{27}$ hay que entender el fenómeno en el marco de la disputa entre dos facciones del empresariado local. Esto nos aleja del criterio de eficiencia abstracto planteado por la historiografía neoinstitucionalista, al sostener que este tipo de regulación tiene por 
objeto solucionar imperfecciones de mercado al garantizar la calidad de la producción, dejando de lado los conflictos sociales que emanan de la normativa (Richadrson, 2008; Epstein 1998; 2007; Gustafsson, 1987). ${ }^{28}$

A partir de la década del ' 50 encontraremos a los pelaires tratando de reforzar la explotación de la mano de obra artesanal. En 1458 logran que el concejo baje los precios del tejido. ${ }^{29}$ Esto representa un avance con respecto a lo visto anteriormente, dado que a la intervención en el proceso de trabajo se suma la fijación de los costos de la actividad. Por otra parte, se refuerza el control sobre el proceso productivo de las actividades preliminares. En este caso, se establece que las urdidoras deban darle a la urdimbre una longitud mínima de cuarenta varas, de lo contrario serían penadas. ${ }^{30}$

Unos años más tarde, en 1467, los veedores de los pelaires denuncian que muchos miembros de su corporación son estafados por oficiales tejedores, ya que estos "les trocan las filazas de los dichos paños e cordellates que les dan a texer e les ponen en sus paños e cordellates otras filazas muy malas" (Martínez Martínez, 2000: 126). ${ }^{31}$ Aquí los pelaires aparecen como dueños de la materia prima, que entregan a otros menestrales para su elaboración, lo que es propio del llamado Verlagssystem. Ahora bien, en la denuncia se observa que los tejedores combinan el trabajo por encargo con cierta actividad independiente, lo que es característico de una situación transicional en la que los productores no han sido completamente separados de los medios de producción. ${ }^{32}$ Por ende, los afectados proponen que se prohíba a los artesanos en cuestión comprar hilaza para fabricar paños, ya sea para vender o vestirse, a lo que el concejo accede.

Esta medida es sumamente importante debido a su potencial para transformar la estructura social de la industria murciana. Al coartar la actividad independiente de los tejedores se logra su completa subsunción al capital, más allá de que conserven la propiedad sobre sus herramientas de trabajo. Esta es una forma específica de acumulación originaria, posible en tanto las autoridades concejiles obturan el acceso de estos artesanos a la materia prima fundamental para el ejercicio de su actividad. Antes de que les fuera prohibida la compra de hilaza, estos disponían de los medios materiales para producir de forma independiente. Por ello la intervención del poder política resulta fundamental para la conversión de la fuerza de trabajo del tejedor en mercancía.

Hemos señalado cómo todas las fases preliminares de la pañería se encontraban sujetas al capital, dado que los artesanos abocados a estas carecían de la capacidad para desempeñarse de forma independiente, lo que los obligaba a trabajar como asalariados al servicio del dueño de la lana. Por el contrario, el gremio de los tejedores, amparado en la estructura corporativa, poseía cierta capacidad de resistencia. Esta medida significaría la derrota definitiva de esta corporación al quebrar el último resabio de su autonomía artesanal. De allí en más, los tejedores solo podrían elaborar paños por su cuenta de forma excepcional, solicitando especialmente una licencia concejil a tal efecto. ${ }^{33}$

Podría objetarse que es difícil sopesar si semejante ordenanza fue de cumplimiento efectivo. Pero el hecho de que a partir de ese año los representantes de la pelairía dejen de solicitar al concejo que intervenga para disciplinar a los tejedores es un indicio de la derrota de este gremio. En este sentido, se puede suponer que se cierra un ciclo de avance pelaire sobre los tejedores tras casi un siglo de conflictos. Por otra parte, en las ordenanzas de la ciudad de 1536, el título correspondiente a los tejedores permite evaluar el efecto a mediano plazo de esta normativa. Lejos de dar indicios actividad independiente, en estas ordenanzas los tejedores figuran trabajando por encargo con materias primas ajenas y se penan los posibles errores y estafas que estos pudieran cometer (González Arce, 2003: 63). ${ }^{34}$

Simultáneamente, encontramos que los pelaires apelan al concejo para garantizar la integridad de los paños que estos entregan a los tintoreros para completar el ciclo productivo, tanto propios como de terceros. El problema radica en que estos y sus mozos "duermen en ellos y aun se horinan. Por cabsa de lo qual los dichos paños se manchan, de tal manera que por ellos valen menos e la tinta no puede remediar los dichos tintoreros” (Martínez Martínez, 2000: 146).Las autoridades concejiles prohíben esta práctica dañina. 
Por otra parte, en este período los representantes de la pelairía solicitan la intervención concejil con el objeto de disciplinar al oficio de los tundidores. ${ }^{35}$ Como señalamos en la introducción, estos artesanos se encontraban subordinados institucionalmente. De esta forma, los tundidores estaban sujetos a la supervisión de los veedores de la pelairía, quienes les imponían directrices técnicas y precios. A la vez estaban obligados a abonar las fianzas del oficio. ${ }^{36}$ A pesar cumplir con estas obligaciones, los tundidores carecían de los derechos gremiales más básicos como participar en la redacción de ordenanzas o en la elección de veedores (González Arce, 2000: 193-4).

Por este motivo, en 1465, estos menestrales comienzan a pugnar por formar una corporación separada, resistiendo a ser examinados por los veedores de la pelairía y a otorgar fianzas a la corporación. Tras la denuncia pelaire, el concejo resuelve que "amos oficios de perayles e tondidores son de una condiçion” (Martínez Martínez 2000: 111), por ende estos últimos seguirían sujetos a las ordenanzas de la pelairía y a la jurisdicción de sus veedores. Sin embargo, esto no es más que el comienzo de un conflicto que se irá agudizando con el correr de los años, en la medida en que el tundido adquiera cada vez más importancia.

$\mathrm{Al}$ igual que los tundidores, los cardadores y peinadores de lana son subordinados dentro del gremio de la pelairía. Como señalamos en la introducción, en 1486 los veedores de la pelairía presentan ordenanzas para regular el trabajo de estos artesanos abocados a las operaciones preliminares del ciclo productivo. La normativa presentada buscaba evitar daños sobre la lana que recibían estos artesanos para ser preparada para las fases sucesivas. Para ello, los pelaires regulan de forma minuciosa las características que deben tener las cardas con las que trabajan dichos operarios. En caso de que sus medios de producción no cumplieran con lo requerido, se instrumentan distintas medidas coercitivas que implican sanciones económicas y, en casos extremos, la destrucción de las cardas. ${ }^{37}$

\section{C. Importación textil y supervisión pelaire}

Se observa cómo a partir de la década del ' 40 el concejo tiende a permitir que el oficio de la pelairía avance sobre las prerrogativas del resto de los oficios textiles, lo que supone una diferencia con el período anterior. Este cambio en la política concejil aparece relacionado con el rol que va a comenzar a jugar el gremio de los pelaires en el control de la producción textil foránea que ingresa a la ciudad, en conjunto con los jueces ejecutores del concejo. De esta manera, las autoridades municipales se sirven del conocimiento específico de estos artesanos con el objeto de regular el mercado local.

En este período el concejo habilita la entrada de paños e hilazas procedentes del ámbito rural y de las villas menores de la región para ser acabados en la ciudad, articulándose un circuito productivo urbanorural. ${ }^{38} \mathrm{~A}$ la par ingresaban productos finalizados, listos para ser vendidos. El punto de inflexión se produce en 1437, con el objeto de que la ciudad esté mejor provista, ya que la producción local no da abasto, lo que redunda en un encarecimiento desmedido de los precios. ${ }^{39}$ Los paños (e hilazas) procedentes del área rural circundante a Murcia y de villas menores (Cartagena, Lorca, Alhama, Librilla, Mula, Cotillas, Jumilla, Hellín, Caravaca, Jorquera, así como las villas del Marquesado de Villena) reciben el nombre de manchegos (Martínez Martínez, 1988: 129).

La calidad de estos paños es inferior a la de los producidos íntegramente en la ciudad, pues están elaborados con procedimientos rudimentarios, son más angostos, tienen menos lana y de peor calidad (Martínez Martínez, 1988: 129; González Arce, 2000: 212). Sin embargo, vemos que resultan imprescindibles para lograr el abastecimiento urbano en un contexto en el cual la producción estrictamente local no es suficiente. A la par, los paños manchegos por finalizar representan un estímulo para la pañería murciana, al menos para los sectores abocados a las últimas fases del ciclo productivo. Por ende, el concejo permite la entrada de los textiles foráneos, aunque debe instrumentar los controles necesarios para evitar los posibles efectos adversos sobre el mercado local. 
Las autoridades municipales pretenden impedir los perjuicios derivados de la posible indistinción entre la producción foránea (finalizada o por finalizar) y la local, que afectan a consumidores y productores locales por igual. En primer lugar, la equiparación mercantil de productos de calidades distintas genera un desajuste entre valores y precios, en tanto "los que tenian paños de la çibdad los auian de vender por menos preçio de lo que valian, e los que tenian paños de fuera los vendían por mayores presçios de su valor" (Martínez Martínez 2000: 60). ${ }^{40}$ Esto redunda en una estafa para aquellos consumidores que compraran paños por encima de su valor, lo que constituye una forma de intercambio desigual. ${ }^{41} \mathrm{~A}$ la vez, los productores locales se ven obligados a vender sus paños a por debajo de su valor, lo imposibilita la realización de la totalidad de la plusvalía contenida en estos.

El segundo problema que se desprende de la indiferenciación entre la producción local y la foránea pasa por el desprestigio de los textiles urbanos. Como hemos señalado, la importación pañera permite la articulación de un circuito productivo urbano rural, en tanto llegan a la ciudad paños e hilazas que son finalizados por mano de obra calificada, inexistente en el ámbito extraurbano. Los bienes resultantes son de una calidad inferior a los elaborados de forma íntegra en Murcia. Por ende, la indistinción entre estos paños afecta al prestigio de la pañería murciana. Esto podía traer problemas tanto para su venta local como para su exportación, lo que es denunciado por los productores. ${ }^{42}$

Es interesante analizar cómo a partir de 1437 el concejo ensaya distintas alternativas para enmendar los problemas ocasionados por la apertura del mercado local. En un principio, dispone medidas de corte restrictivo. Por un lado, se prohíbe que los paños resultantes del circuito productivo urbano rural sean señalados con la marca de la ciudad, lo que es controlado por los veedores de la pelairía. ${ }^{43}$

En relación a la venta de paños finalizados, las autoridades municipales resuelven en 1439 que los paños extranjeros se vendan en dos boticas especiales, dedicadas exclusivamente a dichos bienes. ${ }^{44} \mathrm{Al}$ no resultar suficiente esta medida, al mes de su disposición, el concejo propone controles más estrictos. Los paños rurales deberían ser manifestados en la aduana e inspeccionados por los veedores de los tejedores y pelaires. Luego, estos serían exhibidos de forma conjunta con los paños locales, de modo que se daba marcha atrás con la venta en tiendas separadas, pero se tomaban recaudos para que los productos fueran fácilmente distinguidos. Los paños locales ostentarían la señal de la eme, marca de la ciudad. Los foráneos serían desorillados, sellados con cera bermeja y portarían un papel con la leyenda "este pano no es de la çibdad" (Martínez Martínez 2000: 61).

Sin embargo, el resultado inmediato de esas medidas fue contraproducentes para el tráfico textil, generando "menoscabo de los paños extranjeros. Por la qual razon, los mercaderes cesan de los traher a vender en esta çibdad e por esto encareçen los paños en ella, lo qual es daño del pueblo" (Martínez Martínez 2000: 62). Por ende, las autoridades municipales se verán obligadas a flexibilizar el control de los paños foráneos, para lo cual los veedores de la pelairía serán de crucial importancia. Estos estarán encargados de examinar los textiles importados, bollando los paños que carecieran de defectos, de modo que se los equiparaba a los de la ciudad. En cambio, aquellos que fueran defectuosos serían desorillados y se les coserá un papel en el que se especificase su defecto. Así, es a partir del ojo experto del pelaire que las autoridades concejiles logran regular el mercado pañero.

A partir de 1446 se instrumenta una medida similar para aquellos paños que llegaran a Murcia para ser finalizados: se permitirá que los textiles elaborados parcialmente en el ámbito rural lleven la marca de la ciudad, siempre y cuando su calidad fuera satisfactoria; mientras que a aquellos que resultaran deficientes se les quitaría una orilla. ${ }^{45}$

Durante las décadas siguientes existen numerosas menciones a los veedores de los pelaires desempeñándose en el control de los paños importados. ${ }^{46}$ La novedad radica en que a partir de 1459 estos aparecerán, junto a los ejecutores de la ciudad, tasando a aquellos paños cuya calidad no se equipara a la de los productos locales. ${ }^{47}$ Asimismo, a partir de 1460, por petición del concejo los veedores de la pelairía pasarán a supervisar a la 
totalidad de los paños que se venden en Murcia, sin importar su procedencia. ${ }^{48}$ De esta forma, terminan de convertirse en una pieza clave para la regulación del comercio textil. ${ }^{49}$

Por último, debemos señalar que la regulación del mercado pañero permitía cierto margen de manipulación para favorecer intereses políticos determinados. Esto se evidencia en una ordenanza de 1471, en la cual se exime del control pelaire a los paños procedentes de los dominios pertenecientes al adelantado Don Pedro Fajardo, quien poseía una notable ascendencia sobre el concejo de la ciudad. ${ }^{50}$ Dichos paños quedaban equiparados automáticamente a los paños secenos murcianos. ${ }^{51}$ De esta manera, lejos de una mera eficiencia económica es posible identificar intereses concretos detrás de la normativa.

En el análisis precedente, encontramos que a partir de 1437 el concejo comienza a delegar funciones vinculadas al control de la calidad de los productos textiles de forma progresiva, partiendo de la producción importada de áreas rurales para culminar con la totalidad de los paños que se comercializan en Murcia. A partir del desempeño de esta función, la dirección del gremio puede presionar al concejo para obtener una regulación que le permita subordinar al artesanado textil local y ejercer el control sobre el proceso productivo en una estructura industrial descentralizada.

\section{D. La competencia con los traperos locales en el último cuarto del siglo XV}

Hemos visto cómo en el período anterior la elite pelaire logra imponer condiciones de producción a los distintos oficios textiles que garantizan su acumulación. Hacia fines del siglo XV, estos artesanos devenidos en empresarios han logrado una capacidad productiva que les permite disputar el abastecimiento pañero de la ciudad con los traperos locales, quienes combinan la elaboración de textiles en calidad de señores del pañocon la importación. Con este objeto, los pelaires se servirán de diversos mecanismos institucionales para tratar de evitar la comercialización de textiles por parte de estos últimos.

En primer lugar, la elite pelaire se aprovechará del rol que juega la corporación en la inspección de calidad de la producción textil para limitar la competencia. Anteriormente señalamos que la solicitud pelaire de extender su jurisdicción a las tiendas de los traperos en 1446 debía interpretarse como una herramienta propia de la lucha de clases, dado que contenía como posibilidad la obstrucción de los negocios de estos últimos. A partir de la década del ' 80 encontramos referencias documentales que dan cuenta de la instrumentalización de prácticas de control con ese fin.

En 1481 los mercaderes de paños exponen una serie de agravios ante el concejo producto del accionar de los veedores de la pelairía. Aquellos se quejan del control pelaire por sobre sus paños, tanto los importados como los que producen localmente. En primer lugar señalan que los veedores operan como "espias e acusadores de los arrendadores" (Martínez Martínez 2000: 161) de las rentas municipales y reales, dado que solían denunciarlos en caso de que hubieran omitido el pago de derechos de importación. Más allá de desempeñar una función en la recaudación fiscal, nos interesa destacar que esta acción apunta a reducir el margen de ganancia de los comerciantes de paños y revela la hostilidad entre ambos sectores.

A la vez, los veedores se muestran inflexibles con los paños que encuentran empezados sin la bolla y el sello de calidad correspondientes, dándolos por perdidos. En este punto, los traperos denuncian que a raíz de la normativa vigente, los veedores "por maliçia e malquerencia que con nosotros touiesen por pequeño achaque nos desfaxarian todos nuestros paños” (Martínez Martínez 2000: 162). Las autoridades municipales hacen oídos sordos a estos reclamos.

Unos años más tarde, en 1494, el mercader Guilardo Burgalero denuncia ante el concejo que los veedores Alonso Roldán y Diego Bonilla (ambos pertenecientes a poderosas familias de pelaires locales) rechazan bollar tres paños que trajo para vender en la ciudad. Según el trapero, estos estarían actuando injustamente, dado que los textiles en cuestión habrían tenido la calidad suficiente para pasar el examen. Aduce que había sido perjudicado por su enemistad con Juan Roldán, hermano de uno de los veedores en cuestión. El conflicto 
obedecería a que este trapero no le habría dado anteriormente a este pelaire otros paños para ser adobados, optando por encargar esta tarea a artesanos de Orihuela, para luego venderlos Murcia. ${ }^{52}$

Por otra parte, a partir de la década del setenta las autoridades municipales llevan adelante una política proteccionista que oscilará en virtud de la capacidad productiva local para abastecer al mercado murciano. Las primeras iniciativas corren por parte de los regidores, pero a partir de la década del ' 80 serán los dirigentes de la pelairía quienes impulsen el cierre del mercado local a los textiles foráneos.

En agosto de 1473, el concejo prohíbe la importación de paños mayores de Castilla y Aragón. Estos son paños de calidad media y media alta, aunque no son productos suntuarios como los flamencos. ${ }^{53}$ Unos meses más tarde, la restricción se amplía a los paños manchegos, finalizados o por finalizar. Estos últimos representaban la mayor competencia para la producción de la ciudad (Martínez Martínez, 1988: 134). A la par de proteger a la industria local, estas medidas apuntan a evitar el déficit de la balanza comercial. ${ }^{54}$ Ahora bien, las restricciones a la importación llevan a un faltante de paños, con el consecuente aumento de precios, pues la producción local resulta insuficiente. Por ende, el concejo se ve obligado a flexibilizar su política, otorgando una licencia para importar paños manchegos al mercader que se obligara por los precios más bajos. ${ }^{55}$

En algún momento entre 1476 y 1485, el concejo decide revocar las ordenanzas que restringían la importación pañera, si bien desconocemos la fecha. Semejante medida tuvo un impacto negativo sobre la producción local. Por este motivo, en 1485 , los representantes de la pelairía requieren al concejo que se vete la entrada de paños manchegos. Cabe destacar que los pelaires se presentan como organizadores de la producción local, de quienes dependen "muchas personas pobres menesterosas" (Martínez Martínez 2000: 167) de la ciudad. Así, se observa la protección de la pañería murciana no solo es condición para la acumulación pelaire sino también para la reproducción de un conjunto diverso de asalariados urbanos. Para asegurar el acuerdo, estos se comprometen producir al precio de los paños manchegos, aun cuando sus textiles fueren de una calidad superior. De esta manera, la elite pelaire busca armonizar sus intereses con los consumidores locales.

$\mathrm{Al}$ año siguiente, el concejo eleva a la Corte el pedido realizado por los pelaires, aunque lo amplía a la totalidad de los paños extranjeros. Así, se incluyen los textiles mayores provenientes de Castilla y Aragón, de calidad media o media alta. Como es de esperarse, los paños flamencos son exceptuados de la prohibición. Los Reyes Católicos, tras demandar información al corregidor, acceden a prohibir las importaciones de paños por dos años. ${ }^{56}$ Cumplido este plazo, tras comprobar los efectos beneficiosos de semejante medida, le darán carácter permanente al cierre del mercado local. ${ }^{57}$

Sin embargo, el arrendamiento de la renta de la hermandad de 1489 permite advertir la entrada de paños foráneos de diversas calidades. ${ }^{58}$ Tres años más tarde, a raíz de la insuficiencia de la producción murciana, el concejo suspende la prohibición por dos años. ${ }^{59}$ Por ello, en noviembre de 1496, la elite dirigente volverá a la carga. ${ }^{60}$ En dicho mes, encontramos una petición subscrita por una treintena de pelaires solicitando que se impida por completo la importación pañera. Estos utilizan un argumento recurrente: la llegada indiscriminada de paños extranjeros es perjudicial para el bien común de la ciudad, afectando especialmente a aquellos asalariados que viven de la producción textil. A diferencia de 1485, en donde solamente se buscaba restringir la entrada de paños manchegos, se pretende impedir la entrada de la totalidad de los géneros foráneos.

Los firmantes se obligan a abastecer a la ciudad con paños mayores y menores a precios módicos a partir del año nuevo, poniendo su patrimonio como garantía. El compromiso sería por el lapso de un año. Abarcando textiles que van de los 1600 a los 2200 hilos, la propuesta implica surtir a la ciudad de tejidos de todas las calidades y colores que se requieren, a excepción de los suntuarios de consumo nobiliario. ${ }^{61}$

La novedad de esta propuesta es que conjuga condiciones monopólicas de venta con la fijación de los costos de casi todo el ciclo productivo, a excepción del tintado. ${ }^{62}$ Cardado y peinado de las lanas, hilado, urdido, 
tejido, cardado del paño, y, desde ya, el adobo, son regulados con la sanción política del concejo. Con la salvedad de los cardadores (tanto de paños como de lana), subordinados al gremio de la pelairía, el resto de las operaciones son realizadas por artesanos ajenos a la jurisdicción del oficio pelaire.

Este programa representa el último avance en la construcción de la hegemonía pelaire en la pañería murciana y el intento más sólido de desplazar a los traperos. Ya hemos visto como estos artesanos empresarios han subordinado al artesanado textil local, logrando el control por sobre el proceso productivo en una estructura descentralizada. A esto sumará la fijación minuciosa de los costos de producción y el monopolio del mercado local. Estas son las condiciones necesarias para la reproducción plena de la protoindustria murciana bajo control de los empresarios pelaires, funcionando a su máxima capacidad con el objeto de abastecer a la totalidad de la demanda a precios módicos.

El concejo accede a esta propuesta, aunque con ciertas condiciones. Como es usual, se exceptúan de la prohibición a los paños mayores de Flandes. ${ }^{63}$ Asimismo, los precios originales son rebajados entre un $20 \%$ y un $5 \%$, dependiendo del tipo de paño, siendo la media de la reducción de un 11\%. Esto permite poner en cuestión la tesis de la tradición liberal que asocia el monopolio sobre la venta al establecimiento de precios rentísticos para los gremios, en connivencia con las autoridades urbanas. ${ }^{64}$ Por el contrario, encontramos que los precios de monopolio están sujetos a negociación. Las autoridades municipales, lejos de garantizar una renta, buscan establecer un precio que armonice los intereses de productores y consumidores locales. ${ }^{65}$

Sin lugar a dudas, los grandes perjudicados por esta disposición son los traperos locales. No sólo se ven impedidos de continuar con la importación pañera, sino que en el caso de poseer paños extranjeros, tienen lo que resta del año para venderlos. Una vez cumplido este plazo, se ven forzados a sacarlos fuera del término de la ciudad. Sin embargo, debemos destacar que las autoridades concejiles les ofrecen a estos mercaderes la posibilidad de suscribir la obligación firmada por los pelaires, de manera que pudiesen producir paños localmente bajo las mismas condiciones. En este sentido, el interés del concejo es garantizar el abastecimiento de paños de producción local, sin importar que quienes actúen como verlegers sean pelaires o mercaderes. No obstante, los traperos rechazan participar de la producción en esos términos, ya que no están dispuestos a poner su patrimonio como garantía del abastecimiento pañero de la ciudad. De este modo, solo los pelaires que rubrican la obligación quedan habilitados para ofrecer paños en la ciudad por el lapso de un año. ${ }^{66}$

A pesar de las condiciones monopólicas, los pelaires en cuestión no lograron producir la cantidad necesaria de textiles para satisfacer la demanda murciana, por lo que en junio de 1498 se presentaron ante el concejo para que se reabriera la importación. Las autoridades municipales accedieron y, nuevamente, delegaron en los veedores de la pelairía, junto a los ejecutores del concejo, la supervisión de calidad de los textiles importados. ${ }^{67}$

Más allá de no haber logrado abastecer a la totalidad de la ciudad, nos interesa destacar que los empresarios pelaires hacia fin del siglo XV habían logrado una capacidad productiva que les permitía competir de igual a igual con el capital comercial, personificado en los traperos. Sin embargo, dicha competencia distaba de obedecer a una lógica económica en términos puros, pues implicaba el recurso a elementos políticos para lograr un acceso monopólico al mercado. De esta forma, el uso de la veedoría o la presión sobre el concejo, constituyeron herramientas fundamentales para construir una posición dominante entre las facciones del capital murciano.

\section{Consideraciones finales}

¿Bajo qué condiciones es posible la acumulación en la protoindustria murciana? En el análisis precedente hemos dado cuenta del proceso de construcción del poderío económico de la elite pelaire en la Murcia bajomedieval. Para esto resulta fundamental el impulso de un aparato normativo que le permita controlar el proceso productivo en el marco de una industria descentralizada. De esta manera, el capital pelaire logra subordinar a un conjunto de artesanos que no han sido desposeídos. 
La avanzada de estos señores del paño sobre las condiciones de trabajo de los oficios textiles opera en distintos planos. Por un lado, logran establecer pautas mínimas de calidad para la producción de los diversos oficios relativas a las materias primas y a los medios de producción a utilizar. La anchura de los peines de los tejedores, el material de las cardas de cardadores y peinadores, la cantidad de lana que debe utilizarse en cada paño, entre otros aspectos, son regulados de forma minuciosa.

Por el otro, la elite dirigente de la corporación pelaire logra supervisar el trabajo del artesanado local y así controlar la ejecución correcta de las distintas operaciones. Para examinar la labor de los tejedores, los veedores de la pelairía exceden su jurisdicción original. En cambio, con respecto a cardadores y tundidores, su subordinación como oficios menores al interior del gremio facilita su control. Por último, estos empresarios logran fijar políticamente la estructura de costos de la pañería, estableciendo los salarios de la mayor parte de las operaciones de la cadena productiva.

Los resultados de nuestro análisis nos alejan de los estudios clásicos sobre el fenómeno protoindustrial, ya que estos tienden a presuponer a la libertad de mercado como una condición esencial para el desarrollo económico. ${ }^{68}$ Por ende, la regulación productiva emanada de las corporaciones de oficio es vista como un obstáculo infranqueable para la acumulación de capital. Autores como Kriedte, Medick y Schlumbohm (1986: 40-42, 166, 190-91) advierten que la estructura productiva gremial impone una serie de trabas a la acumulación de capital, como los controles de calidad y precios y el monopolio sobre la oferta de trabajadores. ${ }^{69}$ Estas tienen por objeto asegurar la reproducción del colectivo artesanal como productores de valores de uso. De ahí que el capital debiera trasladar la producción al espacio rural, donde no operan las restricciones gremiales a la acumulación. ${ }^{70}$

A la vez, los resultados de nuestro análisis difieren con los postulados de la historiografía neoinstitucionalista en torno a las corporaciones de oficios. Esta corriente, en oposición la teoría de la protoindustria, encuentra en la regulación gremial un estímulo al desarrollo económico. Esta opera como una respuesta no mercantil a las imperfecciones del mercado, incapaz de funcionar de manera autónoma. En líneas generales, se plantea que los gremios reducen los costos de transacción. Estos son entendidos como el costo de usar el mecanismo de los precios, de cuyo nivel depende el desarrollo del intercambio. ${ }^{71}$ En este sentido, la estructura gremial facilita el desarrollo mercantil.

Según el neoinstitucionalismo, una de las virtudes de la regulación corporativa pasa por reducir los costos derivados de la coordinación de procesos productivos complejos. Así, los gremios actuarían como si fueran firmas, ${ }^{72}$ internalizando costos de negociación de contratos y de vigilancia, en un contexto en el cual la producción aparece fragmentada (Pfister, 2008: 29-32; Mocarelli, 2008:170; De Moor, 2008: 200). El control de múltiples talleres artesanales por parte del empresario del paño implicaría un gasto desmedido. De ahí que la estructura gremial permita bajar los costos de transacción derivados de la necesidad de supervisar el proceso productivo. ${ }^{73}$ De esta manera, los gremios constituyen un arreglo institucional eficiente, que contribuye a lograr un mercado competitivo, escenario ideal para el desarrollo protoindustrial.

Esta corriente tiene el mérito de haber reconocido la posibilidad de desarrollo capitalista en el marco de un sistema productivo dominado por los gremios. Sin embargo, el criterio abstracto de eficiencia propio del análisis neoinstitucionalista limita la posibilidad de comprender las relaciones sociales de producción. De este modo, evaluar los efectos de la regulación productiva y la vigilancia institucional exclusivamente en términos de reducción de costos resulta superficial, pues se pierde de vista su rol en la construcción de relaciones de explotación en la protoindustria, como en el caso que hemos estudiado.

En este punto, nuestro análisis se acerca a los postulados de Iradiel (1973) y Asenjo González (1991) en torno a la importancia de la regulación como medio para que el capital imponga pautas de producción y supervisión acordes a sus necesidades, disminuyendo la libertad técnica de los oficios. ${ }^{74}$ Ahora bien, ambos autores plantean que la acumulación de capital se desarrolla en paralelo a un aniquilamiento de la capacidad de supervisión de la producción por parte de las corporaciones gremiales, que es absorbida por las autoridades 
concejiles. De esta forma, el margen de actuación gremial quedaría limitado al campo religioso y confraternal. Por el contrario, en la protoindustria murciana, el desempeño de funciones vinculadas al control de calidad de los textiles que circulan en el mercado local por parte de la corporación pelaire es el fundamento para la construcción de su poder de mando en la industria. Lejos de ser despojada de sus atribuciones, el concejo tiende a delegar tareas que no son estrictamente productivas en esta corporación, lo que permite que sus dirigentes se consoliden en tanto señores del paño.

Hemos intentado demostrar cómo la inspección de estos textiles resulta fundamental para el mercado local. La entrada indiscriminada de paños foráneos afecta tanto a consumidores como productores murcianos, debido a la equiparación de sus precios con los productos locales de mayor calidad. Por el contrario, una rigidez excesiva en los controles tiende a generar el desabastecimiento del mercado urbano. De ahí que sea necesario el ojo especializado del pelaire para evaluar la calidad de la producción importada y lograr que se venda a su "justo precio", evitando perturbaciones.

Por último, cuando estos artesanos devenidos en empresarios están en condiciones de disputar el abastecimiento local a los mercaderes de paños, obtienen el aval concejil, que dispone en distintas ocasiones el cierre de la importación textil. En este punto, las autoridades municipales, si bien buscan favorecer a los productores locales, fundamentalmente apuestan por lograr el abastecimiento urbano en las mejores condiciones posibles. Por este motivo, lejos de permitir precios rentísticos, imponen precios a la baja para garantizar el interés de los consumidores locales, así como no dudan en abrir las importaciones ante un faltante de paños.

Por ende, el impulso concejil a la pañería local no debe interpretarse como una respuesta directa a intereses sectoriales. Este forma parte de una política más amplia que tiene como norte garantizar el consumo de los habitantes de la ciudad. Es de esta manera como, en el intento de las autoridades municipales por lograr el abastecimiento urbano, la elite pelaire encuentra el espacio para la acumulación de capital.

\section{DOCUMENTACIÓN EDITADA}

Iradiel, Paulino (1974). La Evolución de la Industria Textil Castellana en los siglos XIII-XVI. Factores de desarrollo, organización y costes de la producción manufacturera en Cuenca. Salamanca: Ediciones de la Universidad de Salamanca. Apéndice documental.

González Arce, José Damián, (2003). Ordenanzas de la ciudad de Murcia (1536), Murcia: Universidad de Murcia.

Martínez Martínez, María, (2000). Documentos relativos a los oficios artesanales en la baja Edad Media, Colección de Documentos para la Historia del Reino de Murcia XXI, Murcia: Academia Alfonso X el Sabio.

Torres Fontes, Juan (1976) “Genoveses en Murcia (siglo XV)”, Miscelánea medieval murciana, 2, 71-168. Apéndice documental.

Veas Arteseros, Francisco, (1985). Documentos del siglo XIV (II). Colección de Documentos para la Historia del Reino de Murcia X, Murcia: Academia Alfonso X el Sabio.

\section{Bibliografía}

Asenjo González, María (1991). “Transformación de la manufactura de paños en Castilla. Las ordenanzas generales de 1500". Historia. Instituciones. Documentos, 18, 1991, 1-38.

Astarita, Carlos (2009). Desarrollo desigual en los orígenes del capitalismo. El intercambio asimétrico en la primera transición del feudalismo al capitalismo. Mercado feudal y mercado protocapitalista. Castilla, siglos XIII a XVI, Buenos Aires: Tesis 11 Grupo Editor, Reedición digital.

Banaji, Jairus, (2010). Theory as History, Leiden: Brill.

Banaji, Jairus (2016). "Merchant Capitalism, Peasant Households and Industrial Accumulation: Integration of a Model”, Journal of Agrarian Change, 16(3), 410-431. 
Barrio Barrio, Juan Antonio, (2007). "Las reformas de la industria textil en la pañería de Orihuela en la primera mitad del siglo XV.” Miscelánea Medieval Murciana, 31, 39-68.

Bhaduri, Amit, (1998). "Eficiencia económica e instituciones agrarias.", Historia Agraria, 15, 15-25.

Gustafsson, Bo (1987). "The rise and economic behaviour of medieval craft guilds an economic-theoretical interpretation", Scandinavian Economic History Review, 35(1), 1-40.

Bordes, Josep, (2006). Desarrollo industrial textil y artesanado en Valencia de la conquista a la crisis (1238-1350), Valencia, Comité Económico y Social de la Comunidad Valenciana.

Caracaussi, Andrea, (2016). "Information asymmetries and craft guilds in pre-modern markets: evidence from Italian proto-industry”, The Economic History Rewiew, 70(2), 1-26.

Casado Alonso, Hilario, (2004) "Guilds, Technical Progress and Economic Development in preindustrial Spain" en Massa, Paola. y Moili, Angelo (eds), Dalla corporazione al mutuo soccorso. Organizzazione del lavoro tra XVI e XX secolo (pp. 309-327). Milano: Franco Angeli.

Colombo, Octavio, (2011), "El intercambio desigual en los mercados locales", Edad Media. Rev. Hist., 12, 215-242.

Coase (1937) “The Nature of the firm”, Economica, New Series, 4 (16), 386-405.

Córdoba de la Llave, Ricardo, (2011) "Los batanes hidráulicos de la cuenca del Guadalquivir a fines de la Edad Media. Explotación y equipamiento técnico", Anuario de Estudios Medievales, 41(2), 593-622.

Córdoba de la Llave, Ricardo (2017). Los Oficios Medievales, Madrid: Síntesis, 2017.

Da Graca, Laura, (2016). "Industrias rurales y diferenciación social. Testimonios en piedrahíta y sus alrededores (siglo XV)", Historia. Instituciones. Documentos, 43, 115-140.

De Moor, Tine, (2008). "The Silent Revolution: a new perspective on the emergence of commons, guilds and other forms of corporate collective action” en Lucassen, Jan, De Moor, Tine y van Zanden, Jan Luiten (eds.), The Return of the Guilds (179-212), New York: Cambridge University Press.

Deyá Bauzá, Miguel José, (1996). La manufactura de la lana en Mallorca (1400-1700). Gremios, artesanos y comerciantes. Tesis doctoral inédita, Recuperada de: https://www.tesisenred.net/handle/10803/9405

Ehmer, Josef, (2008), "Rural Guilds and Urban-Rural Guild Relations in Early Modern Central Europe" en Lucassen, Jan, De Moor, Tine y van Zanden, Jan Luite (eds.) The Return of the Guilds (pp. 143-158), New York: Cambridge University Press.

Epstein, Stephan, (1998). "Craft Guilds, apprenticeship and technological change in preindustrial Europe", The journal of economic history, 58(3), 684-713.

Epstein, Stephan (2007). Libertad y crecimiento. El desarrollo de los estados y de los mercados en Europa. 1300-1750, Valencia: PUV.

Falcón Pérez, María Isabel, (1993). "La industria textil en Teruel a finales de la Edad Media”, Aragón en la Edad Media, 10-11, 59-80.

García Sanz, Ángel, (1996), "Verlagssystem y concentración productiva en la industria pañera de Segovia durante el siglo XVIII", Revista de historia industrial, 10, 11-36.

González Arce, José Damián. (2000). Gremios, producción artesanal y mercado. Murcia, siglos XIV y XV. Murcia: Universidad de Murcia.

Hilton, Rodney (1978). Siervos liberados. Los movimientos campesinos medievales y el levantamiento inglés de 1381, Madrid: Siglo XXI.

Iradiel, Paulino (1974). La Evolución de la Industria Textil Castellana en los siglos XIII-XVI. Factores de desarrollo, organización y costes de la producción manufacturera en Cuenca. Salamanca: Ediciones de la Universidad de Salamanca.

Iradiel, Paulino (2017) "En el Mediterráneo occidental peninsular: dominantes y periferias dominadas en la baja Edad Media." En Iradiel, Paulino (comp.) El Mediterráneo Medieval y Valencia. Economía, sociedad, historia (289-322), Valencia: PUV.

Izquierdo Benito, Ricardo, (1988). La industria textil de Toledo en el siglo XV, Toledo: Caja de Ahorro de Toledo 
Kriedte, Peter, Medick, Hans y Schlumbohm, Jürgen, (1986). Industrialización antes de la industrialización, Barcelona: Crítica.

Llibrer Escrig, Josep Antoni, (2013). "Artesanos ante la justicia: la organización de la industria textil medieval a través de la documentación judicial: el ejemplo contestano (1470-1492)”, Historia. Instituciones. Documentos, 40, 123-151.

Llibrer Escrig, Josep Antoni (2014). Industria Textil y crecimiento regional: La vall D'Abaida y el Comtat en el siglo $X V$, Valencia: Universitat de Valencia.

Llibrer Escrig, Josep Antoni (2014 b). “Artesanos emprendedores en la industria textil. Del taller al mercado: el caso del pelaire contestano Bernat Martí (1469-1482)”, En la España Medieval, 37, 295-317.

Martínez Martínez, María, (1988). La industria del vestido en Murcia (ss. XIII-XV), Murcia: Academia Alfonso X el sabio.

Medick, Hans, (1988). "Industrialization before industrialization? Rural industries in Europe and the genesis of capitalism", The indian economic and social history review, 25(3), 371-84.

Mendels, Franklin, (1972). “Proto-Industrialization: The First Phase of the Industrialization Process", The Journal of Economic History 32(1), 241-261.

Mocarelli, Luca, (2008). “Guilds Reappraised: Italy in the Early Modern Period”, en Lucassen, Jan, De Moor, Tine y van Zanden, Jan Luite (eds.), The Return of the Guilds (pp. 159-178), New York: Cambridge University Press.

Molina Molina, Angel Luis, (1976). "Mercaderes genoveses en Murcia durante la época de los Reyes Católicos (1472-1516)", Miscelánea medieval murciana, 2, 278-312.

Moyano Martínez, Juan Manuel (1993), “Los oficiales del Concejo de Murcia (1370-1500)”, Murgetanana, 86, 47-64.

Navarro Espinach, Germán. (2000), "Los negocios de la burguesía precapitalista valenciana de los siglos XV-XVI", Revista d'Historia Medieval, 11, 67-104.

Navarro Espinach, Germán. (2015), "Corporaciones de oficio y desarrollo económico en la corona de Aragón, 1350-1550”, AREAS, 32, 21-31.

Navarro Espinach, Germán. (2018), "El oficio de los pelaires de Valencia a través de sus asambleas de 1452-1481", en El Pais Valenciano en la Baja Edad Media: estudios dedicados al profesor Paulino Iradiel (pp. 281-307), Valencia: PUV.

Ogilvie, Sheilagh, (1993), "Social institutions and proto-industrialization" en Ogilvie, Sheilagh y Cerman, Makus (eds.), European proto-industrialization (23-37), Cambridge: Cambridge University Press.

Ogilvie, Sheilagh, (2004) "Guilds, efficiency, and social capital: evidence from German proto-industry", Economic History Review, 57(2), 286-333.

Ogilvie Sheilagh, (2007). “'Whatever Is, Is Right'? Economic Institutions in Pre-Industrial Europe”, The Economic History Review, New Series, 60(4), 649-684.

Perelman Fajardo, Marcelo Emiliano (2018). "El problema historiográfico de la transición del esclavismo al colonato", Anales de Historia Antigua, Medieval y Moderna, 52, 137-163.

Pfister, Ulrich, (2008). “Craft Guilds, the Theory of the Firm, and Early Modern Proto-industry”, en Epstein, Stephan y Prak, Maarten (eds.) Guilds, Innovation, and the European Economy, 1400-1800 (pp. 172-198), New York: Cambridge University Press.

Piqueras García, María Belén (1987-8). "El funcionamiento del Concejo Murciano (1462-1474)”, Miscelánea Medieval Murciana, 14, 9-47.

Poni, Carlo, (1985). “Proto-industrialization, rural and urban.” Review (Fernand Braudel Center), 9(2), 305-314.

Prak, Maarten, Crowston, Clare, De Munck, Bert, Kissane, Christopher, Minns, Chris, Schalk, Ruben y Wallis, Patrick (2018), "Access to the trade: monopoly and mobility in European craft guilds, 17th and 18th centuries", Economic History working papers (282/2018), London School of Economics and Political Science, London, UK.

Richardson, Gary, (2008) “Brand names before the industrial revolution”, NBER working papers, Working Paper 131930, recuperado de: http://www.nber.org/papers/w13930 
Riera I Melis, Antoni, (1993), “La aparición de las corporaciones de oficio en Cataluña (1200-1350)”, en Cofradías, gremios, solidaridades en la Europa Medieval. XIX Semana de Estudios Medievales de Estella (pp. 285-318), Pamplona: Fondo de Publicaciones del Gobierno de Navarra.

Schlumbohm, Jürgen, (1996). "Proto-industrialization as a research strategy and a historical period- a balance sheet" en Ogilvie, Sheilagh y Cerman, Markus (eds.) European proto-industrialization (pp. 12-22), Cambridge: Cambridge University Press.

Smith, Adam, (2014). Investigación sobre la naturaleza y causas de la riqueza de las naciones. México: Fondo de Cultura Económica.

Thrupp, Sylvia, (1965). “The Guilds” en Postan, M.M, Rich E.E y Miller, E. (eds), The Cambridge Economic History of Europe Vol.III (pp.230-280), Cambridge: Cambridge University Press.

Torres Fontes, Juan (1976) “Genoveses en Murcia (siglo XV) Miscelánea medieval murciana, 2, 71-168.

Torres Fontes, Juan (1987) “Evolución del Concejo de Murcia en la Edad Media.”, Murgetana, 71, 5-47.

\section{Notas}

1 Para una descripción minuciosa del proceso productivo textil ver Martínez Martínez (1988), Iradiel (1973), Falcón Pérez (1993), Izquierdo Benito (1988), Córdoba de la Llave (2017), entre otros.

2 Junto al salario, los empleadores solían ofrecer un refrigerio, práctica que sería prohibida por las autoridades concejiles reforzando así la explotación de la mano de obra. Ver Archivo Municipal de Murcia [en adelante AMM] Actas Capitulares [en adelante AC] 1384-5, 2/7/1384, 15v.

3 Martínez Martínez (2000), doc.140, 19/11/1486.

4 Esta es una actividad originariamente vinculada a la reproducción de la unidad doméstica que, en el período que nos ocupa, se mercantiliza. Su carácter femenino puede verse reflejado en la cultura popular medieval. En los sermones atribuidos a John Ball durante el levantamiento inglés de 1381: "Whan Adam delf and Eve span, wo was thanne a gentilman”. Citado en Hilton (1978: 280).

5 En 1473 encontramos un pregón que señala que ante un faltante de lana las mujeres pobres de la ciudad no tenían de qué vivir. Martínez Martínez (2000), doc. 127, 9/1/1473

6 Para el funcionamiento de los molinos batanes ver Córdoba de la Llave (2011)

7 Será el capital italiano el que intente subordinar a los tintoreros locales durante el período estudiado, fenómeno que excede al presente trabajo. Ver Torres Fontes (1976) y Molina Molina (1976).

8 El hecho de que la fragmentación del proceso productivo permita la emergencia de acumuladores capitalistas que le den cohesión ha sido señalado en la historiografía. Para un planteo general ver Sylvia Thrupp (1965: 264-5). Existen numerosos casos en la península ibérica en los cuales miembros de la pelairía desempeñan dicha función. Para Cocentaíana, ver Llibrer Escrig (2013; 2014 y 2014b), para Mallorca, Deyá Bauzá (1996:125), para Valencia, Navarro Espinach (2000:77) y Barrio Barrio (2007) para Orihuela. Por otra parte, podemos encontrar empresarios pelaires con un rol protagónico en el desarrollo de industrias rurales, como demuestra Da Graca (2016).

9 Este planteo está inspirado en los trabajos de Jairus Banaji $(2010 ; 2016)$. El autor demuestra que en diversos períodos históricos la clase dominante dirige el proceso de trabajo de productores que, a priori, parecerían estar en control de este.

10 Veas Arteseros (1985), doc. 4 28/7/1374.

11 A.M.M., AC, 1408-9, 3/11/1408, 102 r-v.

12 Esta es una figura de origen musulmán, encargada de controlar pesos y medidas. A comienzos del período estudiado tiene capacidad de supervisión sobre los paños, atributo que luego pierde en la medida que se consolidan los aparatos de supervisión gremiales. Ver Moyano Martínez (1993) y González Arce (2000).

13 En esa calle están establecidos los miembros del oficio de la pelairía.

14 Este tipo de conflicto no habría sido privativo de la pañería murciana. Bordes Garcia (2006) identifica una situación similar en Valencia en 1344, aunque no la analiza de forma pormenorizada.

15 Según Martínes Martínez (1988: 46), esta medida implica un salto cualitativo en la producción local, ya que la introducción de peines más anchos en los telares implica la obtención mejores paños y más competitivos en el mercado. Esta adaptación se generaliza en los núcleos pañeros castellanos de la meseta sur. Ver Izquierdo Benito (1988:72) e Iradiel (1974: 197-8) para Toledo y Cuenca respectivamente.

16 Este conflicto tiene puntos de contacto con lo analizado por Navarro Espinach (2018) para Valencia, donde los pelaires intentan imponer nuevos peines a los tejedores. 
17 Martínez Martínez (2000), doc. 45. 21/2/1413.

18 Por ejemplo, en 1413 el pelaire Domingo Salat aparece entregando a teñir un paño de una mujer de Cartagena, que permanece anónima, al tintorero Ginés Terrés. Martínez Martínez (2000), doc. 46. 22/7/1413. Esta era una práctica común. Ver Deyá Bauzá (1996) para el caso mallorquín.

19 Martínez Martínez (2000), doc.18,30/04/1405 y doc. 27, 8/5/1405.

20 Martínez Martínez (2000), doc. 69, 5/4/1446.

21 Paños de 2100 hilos.

22 Martínez Martínez (2000), doc.73, 8/2/1455.

23 El alumbre es un mordiente de origen mineral que se utilizaba en el proceso de tintado como fijador con el objeto de que los colores prendieran bien en los paños.

24 Cabe aclarar que se trata de paños de una calidad media que provienen de Aragón así como de ciertos lugares de Castilla como Cuenca.

25 Este fenómeno no es privativo de Murcia, sino que encontramos intentos de avances similares en otras ciudades ibéricas en las que el colectivo pelaire protagoniza procesos de acumulación. En Valencia la corporación pelaire logra imponer modificaciones en los medios de producción de los tejedores, ver Navarro Espinach (2000: 76). En Orihuela, los pelaires logran imponer una normativa que regula distintas fases del proceso productivo y las deja bajo la supervisión de los veedores de dicha corporación. Ver Barrio Barrio (2007: 59-62).

26 Martínez Martínez (2000), doc. 69, 5/4/1446

27 Un fraude clásico por parte de los mercaderes es obligar al pelaire a estirar de más el paño al momento de colgarlo luego del batanado para que aparente tener una mayor longitud.

28 Para una crítica a la noción abstracta de eficiencia de esta corriente ver Bhaduri (1998)

29 Martínez Martínez (2000), doc. 79,7/3/1458. Nueve años más tarde, en un contexto inflacionario, el concejo decide elevar el precio del tejido tras una petición de los tejedores. Doc. 106 18/4/1467

30 En este punto existen similitudes con la reglamentación impuesta a los diversos artesanos de los primeros eslabones del ciclo textil de Perpiñán, impulsada por las corporaciones de pelaires y tejedores a comienzos del siglo XIV (Riera I Melis, 1993: 306-7).

31 Otra mención directa a los pelaires entregando materia prima para ser elaborada: Martínez Martinez (2000), doc. 155, $9 / 7 / 1485$

32 Esta es una queja usual de los mercaderes-fabricantes. Véase los informes presentados a la corona a fin de siglo para la elaboración de ordenanzas generales: Iradiel (1974) doc. 26. 1495 y doc. 28. 1495.

33 Como es el caso del tejedor Sancho Sánchez, quien en 1476 obtiene autorización para elaborar paños en su casa, para vestirse y para vender. A.M.M, 1476-7, 30/7/1476, 28v.

34 En estas ordenanzas se refuerzan los mecanismos de control para evitar robos a los dueños de la materia prima. Por ejemplo, los tejedores pasan a estar obligados a pesar la cantidad de hilaza recibida y devolver un paño con un peso equivalente. $\left(\mathrm{n}^{\circ} 12\right)$. Los tejedores valencianos se encuentran sujetos a un nivel de control similar (Navarro Espinach, 2018: 440)

35 Cabe destacar que la corporación pelaire impulsó el desarrollo del tundido en la ciudad como parte de su intento de lograr una pañería de mayor calidad. Con este objeto, en 1438 las autoridades del gremio habían solicitado al concejo que facilitara la instalación en la ciudad de un maestro afilador de tijeras de tundir mediante la franqueza de pechos y la cesión de una casa para que habitara. El concejo accedió a lo solicitado al considerarlo provechoso para la industria local. Martínez Martínez (2000), doc. 58. 27/9/1438.

36 Desde la segunda mitad del siglo XV, los veedores de cada oficio recibían una determinada cantidad de dinero por parte de los artesanos en concepto de fianza. Esta operaba como reaseguro en caso de que los menestrales no cumplieran con las obligaciones pactadas. En la práctica, este ingreso monetario contribuía a solventar los gastos de la corporación. Según Martínez Martínez (1988:288), la fianza debía ser abonada anualmente por todos los artesanos que trabajaran en la ciudad.

37 Martínez Martínez (2000), doc.140, 19/11/1486.

38 Los paños que llegan a Murcia a ser finalizados deben ser batanados, tundidos y teñidos. Según Iradiel (2017: 277) Murcia (al igual que Valencia) actuaría como un centro industrial regional respecto a una periferia abocada a producir productos semielaborados, dado que es incapaz de completar el ciclo textil.

39 Martínez Martínez (2000), doc. 55. 1/10/1437.

40 Es interesante señalar que son los propios representantes de la pelairía los que denuncian esto ante el Concejo, al presentarse con dos paños, uno extranjero y otro local, con diferencias notorias en tanto calidad, pero que se vendían al mismo precio (Martínez Martínez, 2000: 59)

41 Para un análisis del intercambio desigual, ver Colombo (2011). 
42 "los que conprauan aquellos paños de fuera e se fallauan mal dello ponían por fama que los paños de la dicha çibdad eran malos, por la qual razon refusauan de conprar paño de la çibdad”(Martínez Martínez, 2000: 60). Ver asimismo doc. $616 / 9 / 1439$.

43 Martínez Martínez (2000), doc. 55. 1/10/1437 y doc. 60. 25/2/1439.

44 Martínez Martínez (2000), doc. 59. 13/1/1439.

45 Martínez Martínez (2000), doc.69, 5/4/1446.

46 Martínez Martínez (2000), doc. 79, 7/3/1458, doc 82. 10/11/1459, doc. 115, 7/3/1469, doc. 122, 7/3/1471, A.M.M. AC, 1462-3, 21/8/1462, 34 v, A.M.M. AC 1467-8, 12/9/1467, 39v-40r y A.M.M. AC 1469-70, 2/9/1469, 38r.

47 Martínez Martínez (2000), doc. 82. 10/11/1459 y A.M.M, AC, 1463-4, 18/10/1463 f. 42 v. En 1467 los representantes de la pelairía presentan al concejo una lista de precios en la cual los paños manchegos aparecen discriminados: Martínez Martínez (2000), doc. 108. 24/4/1467.

48 Martínez Martínez (2000), doc. 135, 15/7/1460. A la vez, en esta década la corporación pelaire también va a colaborar con la supervisión del tintado. Hemos aclarado anteriormente que el concejo dispone de funcionarios propios, los jueces de tintas, para examinar la labor de los tintoreros. Ahora bien, los veedores de los pelaires se encargarán de elaborar las muestras necesarias para que los dichos jueces puedan cotejar la obra de los artesanos en cuestión. En este sentido, vemos como el conocimiento específico de los pelaires resulta clave para elaborar el sistema de control del ciclo textil. A.M.M. AC, 1460-61, 16/5/1461, 95r.

49 Desde otra perspectiva, la corriente neoinstitucionalista ha señalado que las corporaciones gremiales son fundamentales para el funcionamiento del mercado. Para ello retoman el análisis realizado por Akerlof (1970) en torno al mercado moderno. A diferencia de la teoría neoclásica, que postula que los agentes están en posesión de información perfecta para hacer uso de sus recurso económicos de la forma más eficiente posible, el autor plantea que la información no está disponible en el mercado de por sí, lo que puede llevar a un colapso de los intercambios, en tanto los compradores no cuentan con las garantías necesarias para conocer la calidad de los bienes que adquieren. Aplicando este razonamiento al mercado medieval, el neoinstitucionalismo sostiene que las corporaciones gremiales cuentan con diversos mecanismos para evitar la incertidumbre en el consumidor. Entre estos se destacan el examen a los artesanos, la supervisión permanente de los talleres y la señalización de los productos finalizados con la marca gremial, lo que certifica su calidad. Ver Richardson (2008), Epstein (1998; 2007), Gustafsson (1987). Para una crítica a estos postulados desde el mismo enfoque teórico, ver Caracaussi (2016).

50 Para un análisis de la influencia de Don Pedro Fajardo sobre el gobierno municipal ver Torres Fontes (1987) y Piqueras García (1987-88).

51 Paños de 1600 hilos.

52 AMM AC 1494-5 29/7/1494, ff. 26r-28v. También se menciona el episodio en González Arce (2000:201)

53 Los textiles de Flandes no están destinados al consumo popular, sino que son adquiridos por las oligarquías urbanas. Estos eran bienes de prestigio, fundamentales para ostentar la posición estamental y hacer evidente la separación con respecto al común de los pecheros. Así, el consumo suntuario coadyuva a la reproducción del poder de clase. Para un análisis en profundidad de esta lógica ver Astarita (2009: especialmente capítulos 3 a 5). No existe un equivalente local para estos textiles. Debido a esto, cada vez que las autoridades locales prohíben la importación de paños, excluyen a los flamencos. A la vez, no existe presión alguna por parte de los pelaires para impedir la entrada de dichos textiles, dado que no representan competencia para su producción, en tanto se encuentra destinada al consumo pechero.

54 "por quanto esta çibdad esta muy falta de moneda e aquella poca que ay se saca de cada un dia, en tal manera que, sy en ello non se da algund remedio, antes de poco tiempo las gentes non se podran proueer de las cosas que han necesario para sus mantenimientos." AMM AC 1473-4, 31/8/1473, f.42 v-43r. y AMM AC 1473-4, 14/12/1473, f. 85 r. Debemos destacar que el cierre de las importaciones no se hace efectivo de forma automática, en tanto los traperos cuentan con ciertas artimañas para evadir la prohibición. Por ejemplo, llevando sus productos a la comarca de la ciudad, con el objeto de venderlos fuera de los muros de esta. Estas prácticas serán reprimidas por el concejo. A.M.M. AC 1474-5, 9/7/1474, 48r.

55 A.M.M, A.C 1476-7, 9/10/1476 39v-40r

56 Torres Fontes (1976), doc. 22, 29/5/1486.

57 Torres Fontes (1976), doc. 23, 22/2/1488.

58 Martínez Martínez (2000), doc. 163, 29/9/1489.

59 AMM AC 1491-2, 21/2/1492, 114.r.

60 Martínez Martínez (2000), doc. 175. 17/12/1496.

61 En este sentido, la capacidad productiva de este grupo de pelaires presenta semejanzas con los poderosos maestros tejedores de seda valencianos. Estos últimos, alrededor de trescientos menestrales, tenían en 1512 la capacidad para 
producir 42.000 varas de tejido de seda (Navarro Espinach, 2015: 29). Si bien no es posible avanzar en la comparación en el presente trabajo, sería provechoso hacerlo en un futuro.

62 La ausencia de los precios del teñido de esta propuesta da la pauta de la independencia de los tintoreros con respecto a la pelairía. De hecho, estos artesanos cuentan con canales propios de negociación de precios.

63 Ver nota 53.

64 Ver Smith (2014), Ogilvie (2004; 2007). Esta tesis fue retomada desde el marxismo por Kriedte, Medick y Scluhmbohn (1986).

65 El impedimento de abusos derivados del monopolio por parte de las autoridades locales es señalado correctamente por Gustafsson en relación a las ciudades alemanas (1987:21)

66 Martínez Martínez (2000), doc 174, 26/11/1496.

67 Martínez Martínez (2000), doc.176, 9/6/1498.

68 Este presupuesto no es privativo de la historiografía medieval y moderna. También en la historiografía de la antigüedad clásica está ampliamente difundida la noción de la superioridad económica de formas de producción "libres", como demuestra Perelman Fajardo (2018).

69 Ver también Kriedte (1994: 18-19).

70 Estos autores profundizan el planteo original de Mendels (1972) quien sostiene que el capital debe trasladar la producción al espacio rural dado que allí existen costos menores en comparación con el urbano, aunque no da cuenta de la incidencia de las instituciones feudales en este fenómeno. La tesis de la incompatibilidad entre el desarrollo protoindustrial y las corporaciones de oficio recibió diversas críticas a la luz de la evidencia empírica dado que no se comprueba la exclusión total del espacio urbano del proceso productivo. Ver Poni (1985) y Ogilvie (1993). Incluso los propios autores han tenido que matizar su planteo original. Ver Medick (1988) y Schlumbohm (1996).

71 Para la revisión del desempeño económico de los gremios realizado por el neoinstitucionalismo ver Epstein (1998, 2007, 2008), Epstein y Praak (2008), Lucasen, De Moor y van Zanden (2008), van Zanden (2009), Richardson (2001), Gustafsson (1987),Park, Crowston, De Munck, Kissane, Minns, Schalk y Wallis (2018), Casado Alonso (2004).

72 Para la teoría de la firma en su versión original ver Coase (1937)

73 Desde otra óptica, García Sanz (1996: 20) plantea que los mercaderes-empresarios se sirven del gremio en pos de vigilar la mano de obra.

74 Cabe aclarar que estos trabajos analizan principalmente la regulación emanada por la Monarquía.

\section{BY-NC-SA}

